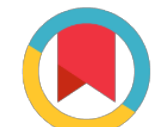

Check for updates
*For correspondence:

hwsung@mx.nthu.edu.tw

Competing interests: The authors declare that no competing interests exist.

Received: 2017-05-04

Accepted: 2017-05-29

Published: 2017-09-05

Copyright The Author(s) 2017. This article is published with open access by BioMedPress (BMP).

This article is distributed under the terms of the Creative Commons Attribution License (CC-BY 4.0) which permits any use, distribution, and reproduction in any medium, provided the original author(s) and the source are credited.

\section{Injectable Cell Delivery Constructs for Myocardial Tissue Engineering}

\author{
Chieh-Cheng Huang a, Ding-Yuan Chen a, Chun-Wen Hsiao a, Wen-Yu Lee a, \\ Yen Chang $b^{*}$, and Hsing-Wen Sung $a^{*}$
}
a. Department of Chemical Engineering and Institute of Biomedical Engineering, National Tsing Hua University, Hsinchu, Taiwan (ROC)
b. Department of Cardiovascular Surgery, Heart Center, Cheng Hsin General Hospital, Taipei, Taiwan (ROC)

\section{Abstract}

Cell transplantation via direct intramuscular injection is a promising therapy for patients with ischemic diseases. However, following injections, retention of transplanted cells in engrafted areas remains problematic, and can be deleterious to cell-transplantation therapy. In this presentation, a thermo-responsive hydrogel system composed of aqueous methylcellulose (MC) blended with phosphate-buffered saline is constructed to grow cell sheet fragments and cell bodies for the treatment of ischemic diseases. The as-prepared MC hydrogel system undergoes a sol-gel reversible transition upon heating or cooling at approximately $32{ }^{\circ} \mathrm{C}$. Via this unique property, the grown cell sheet fragments (cell bodies) can be harvested without using proteolytic enzymes; consequently, their inherent extracellular matrices (ECMs) and integrative adhesive agents remain well preserved. In animal studies using rats and pigs with experimentally created myocardial infarction, the injected cell sheet fragments (cell bodies) become entrapped in the interstices of muscular tissues and adhere to engraftment sites, while a minimal number of cells exist in the group receiving dissociated cells. Moreover, transplantation of cell sheet fragments (cell bodies) significantly increases vascular density, thereby improving the function of an infarcted heart.

These experimental results demonstrate that cell sheet fragments (cell bodies) function as a cell-delivery construct by providing a favorable ECM environment to retain transplanted cells locally and consequently, improving the efficacy of therapeutic cell transplantation.

\section{Keywords}

Funding

\section{References}

